\title{
Effect of practicing Yoga on Aerodynamic measures of Voice
}

Aravinda H.R', Dipti Jog', Kushal Kumar $A^{2}$.

1. Lecturer in Audiology, JSS Institute of Speech and Hearing, Dharwad - 580007, Karnataka, India.

2. Student, BASLP, JSS Institute of Speech and Hearing, Dharwad - 580007, Karnataka, India.

\begin{abstract}
Yoga is a Sanskrit word that interprets the meaning "the unity of body and mind." It is a blend of breathing drills, physical stances, and contemplation. It has been practiced in eastern conventional medicine for more than thousands of years. A modest effort was taken in this study to examine the effect of Long term yoga training on Aerodynamic measures and also to compare and contrast these measures between individuals who practice yoga and who don't. A total of 120 phonation samples were obtained from participants who practice yoga and who don't between the age ranges of 20-40 years. Samples assessing respiratory capacities were also taken from the above subjects. Statistical analysis showed a significant difference $[p<0.05]$ between the control group and the experimental group for all parameters. A significant difference was also seen between genders [ $p<0.05]$. A significant difference was seen in gender within the control group [ $p=0.02]$ and also within the experimental group [p=0.00]. The prevailing study establishes a positive correlation between practicing yoga and betterment in aerodynamic capacities. The results declare that there was significant escalation in vital capacity, maximum phonation duration, phonation quotient, and mean airflow rate for individuals who practice regular yoga when compared to people who don't. The outcome of the present study is a preliminary step towards creating an evidence base for the practice of yoga towards overall aerodynamic improvement in healthy adults.
\end{abstract}

KEYWORDS: Aerodynamics, vital capacity, yoga, Mean air flow rate, phonation quotient.

\section{INTRODUCTION}

Y oga is a Sanskrit word that interprets to the meaning "the unity of body and mind". It is a blend of breathing drills, physical stances, and contemplation, and has been practiced in eastern conventional medicine for more than thousands of years [1]. Yoga furthermore has been described as insight in work or expert living among activities, harmony, and self-control. Yoga is not for him who gorges too much, nor for him who starves himself. It is not for him who steps too much, nor for him who stays awake. By control in intake and resting, by having control in the functioning and by concordance in sleeping and waking, yoga destroys all pain and sorrows" [2]. Yoga is an ancient philosophical and religious tradition that is thought to have originated in India in at least 1000 B.C. It refers to a large body of values, attitudes and techniques whose primary objective is the pursuit of enlightenment or selfknowledge.

Focusing on the respiratory feature of yoga, Pranayama, in general, involves disciplined 
breathing techniques that alter the respiratory measure, specifically through prolongation and shortening of breaths, and occasionally breathholding, all signifying voluntary control of respiratory muscles. It is said that the practice of Ashtang yoga, particularly 'Pranayam', improves both the physical and spiritual health [3]. 'Pranayam' is a Yogic technique in which breathing is controlled voluntarily. There are a variety of methods of Pranayam, the inhalation (puraka), exhalation (rechaka), and maintenance of breath called Kumbhaka (in or out). Entire Pranayama involves unhurried inhalation and exhalation along with apnoea (breath-hold) at end inspiration and end-expiration. The goals are to reduce the breathing pace from usual resting levels of 12 breaths per minute to more or less of six breaths per minute, to attain an approximate 1:2 ratio for a period of inspiration and expiration, and an end-inspiratory breathhold of approximately two times the length of expiration. These breath maneuvers mobilize in series the abdominal muscles, diaphragm, the lower and upper intercostals muscles of chest wall and sternocleidomastoid muscles, and even back muscles are activated [4]. Pranayama also regulates the vital forces of the body and helps in curing lung-related and voice-related disorders [5]-[9]. In normal breathing, the individual generally neglects the posture and the breathing pattern. Throughout the practice of pranayama, one should give attention to the posture and breathing patterns. Therefore the inspired air can be evenly dispersed in the lungs and can take up more volume, which makes the person capable of inspiring intensely and exhale the same quantity of air with no strain [10]. There are studies showing the scientific reasons following the practice of this yoga, pranayama, and its contributions in recuperating the health condition of many pathological cases such as asthma and other respiratory disorders [5].

Pulmonary function is a long term predictor for the whole survival rates in both genders and can be used as an instrument in general health assessment [10]. One of those pulmonary functions is the vital capacity. Vital capacity is the maximum amount of air a person can force out from the lungs following a maximum inspiration [11]. It is equivalent to the inspiratory reserve volume plus the tidal volume and expiratory reserve volume [12]. A typical adult has a vital capacity between three and five liters. The vital capacity of the lungs is a critical component of good health. Normal processes, tissue healing, and athletic performance all depend on effective breathing. There are at least 2 aspects of effective breathing: The proper use of breath controlling musculature, including the muscles of the abdomen, the diaphragm and the intercostals muscles of the thorax and the functioning of the lungs themselves [13]. Maximum Phonation Duration (MPD) is the longest period during which a patient can sustain phonation of a vowel sound, typically /a/.
Former studies have proclaimed benefits of yoga on common heath, especially in disorders like asthma, anxiety, depression, and hypertension [15], with few focusing the effect on aerodynamic measures based on the breathing techniques mentioned in pranayama. Also, there is a need for a concrete structure for the physiological functions of yoga on aerodynamic capacities. Hence the current study explored the effect of regular yoga on the aerodynamic parameters of voice in typical healthy individuals.

A humble effort was taken in this study to examine the effect of Long term yoga training on Aerodynamic measures such as Vital capacity, Phonation Quotient, Mean air flow rate, s/z ratio, and Maximum phonation duration and also to compare and contrast these measures between individuals who practice yoga and who don't.

\section{Materials ANd Methods}

\section{Participants:}

A total of 120 phonation samples for vowel /a/ Aand consonants /s/ and / z/ were obtained from participants between the age ranges of 20-40 years. Sixty samples were collected from 20 individuals (12 males and 8 females) who are well versed in yoga and are practicing yoga for a minimum of one year, and the other 60 samples were taken from 20 (12 males and 8 females) individuals who do not practice yoga. Samples assessing respiratory capacities (Vital capacity, Phonation quotient, and Mean air flow rate) were also taken from the above subjects by instructing them to phonate maximally after a deep inhalation.

Exclusion criteria: Subjects who had any history of a voice problem, breathing difficulty (asthma, bronchitis etc.) smoking and consumption of alcohol were excluded.

\section{Instrumentation:}

A wet spirometer was used to collect and read the respiratory capacities, and a SONY IC Recorder, at a distance of approximately one foot from the subject, was utilized to record the phonation samples. A Casio digital stopwatch was used to calculate the duration of phonation.

\section{Analysis:}

The readings of vital capacity from the spirometer for each individual were noted down, and also phonation quotient was derived by applying the formula $\mathrm{PQ}=\mathrm{VC} / \mathrm{MPD}$. The mean airflow rate was attained from the formula MAFR $=77+(0.236 * \mathrm{PQ}) . \mathrm{MPD}$ was obtained by manually calculating the maximum duration of phonation. Ratio of /s/ and / $z$ / was calculated and tabulated. All the results were tabulated and were subjected to statistical analysis.

\section{RESUlTS}

- tatistical analysis was carried out in SPSS 20 software. Descriptive statistics was done to 
find out the mean and SD for the control group and experimental group. Mean, and SD for MPD of $/ \mathrm{a} /, \mathrm{VC}, \mathrm{PQ}, \mathrm{MAFR}$, and $\mathrm{S} / \mathrm{Z}$ ratio for the control group and experimental group is seen in the figures below.

Table 1 : Showing Mean PQ, MAFR and S/Z ratio of male and female individuals who practice yoga and who do not practice yoga.

\begin{tabular}{|l|l|l|l|l|}
\hline \multicolumn{1}{|c|}{ Mean } & \multicolumn{1}{c|}{$\begin{array}{c}\text { Non Yoga } \\
\text { males }\end{array}$} & Yoga males & $\begin{array}{c}\text { Non Yoga } \\
\text { Females }\end{array}$ & $\begin{array}{c}\text { Yoga } \\
\text { Females }\end{array}$ \\
\hline $\begin{array}{l}\text { Phonation } \\
\text { Quotient } \\
\text { (PQ) }\end{array}$ & 148.65 & 106.68 & 109.78 & 102.66 \\
\hline $\begin{array}{l}\text { Air Flow } \\
\text { Rate } \\
\text { (MAFR) }\end{array}$ & 112.08 & 102.17 & 102.9 & 101.22 \\
\hline S/Z Ratio & 0.94 & 1 & 0.95 & 0.94 \\
\hline
\end{tabular}

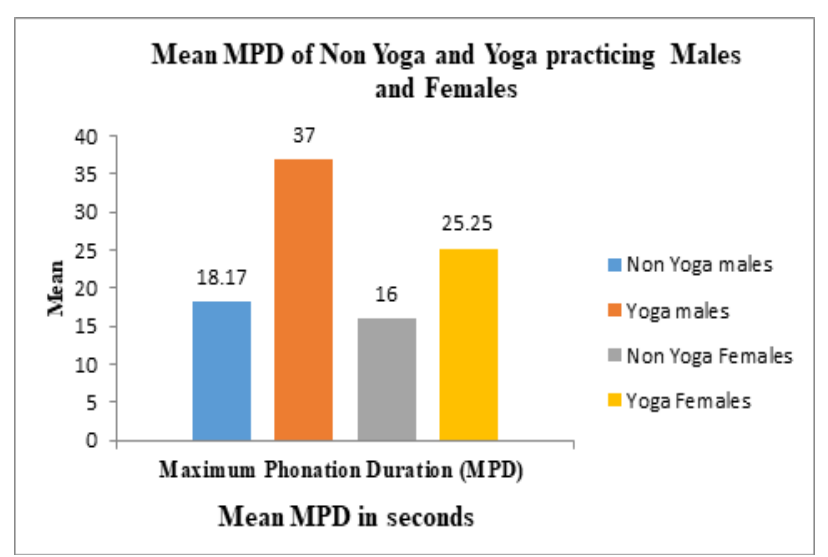

Figure 1. Showing Mean of Maximum Phonation Duration of male and female individuals who practice yoga and who do not practice yoga.

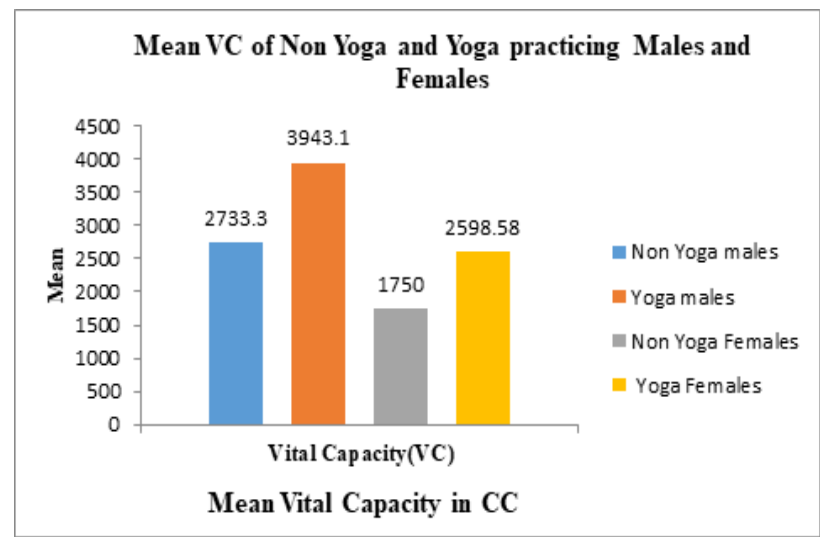

Figure 2. Showing Mean Vital Capacity of male and female individuals who practice yoga and who do not practice yoga.

Test of normality was done, and results indicated a non significance, demonstrating a normal distribution, and hence parametric test was administered. MANOVA was done, and it was found that there was a significant difference [Wilks' $\lambda=0.006, F(6,31.00)=870.6, p<0.05]$ between the control group and experimental group for all parameters except for $\mathrm{S} / Z$ ratio. Significant difference was also seen between genders [Wilks' $\lambda=0.005, F(6,31.00)=1039.47$, $\mathrm{p}<0.05]$. There was a significant difference in the interaction between the group and gender
[Wilks' $\lambda=0.093, F(6,31.00)=50.55, \mathrm{p}<0.05]$ and hence further independent sample T-test was implemented to find out the significance separately between gender within the group and between groups.

Results of $\mathrm{T}$ test pointed out significant difference in gender within control group [t $(18)=3.57$, $\mathrm{p}=0.02$ ] and also within experimental group [t $(18)=21.62, p=0.00]$ for all the aerodynamic parameters except $\mathrm{S} / Z$ ratio. Significant difference was seen for MPD, VC, PQ and MAFR between males vs. males and females vs. females of control group and experimental group respectively [t $(22)=-32.7, \mathrm{p}=0.00]$ and $[\mathrm{t}(14)=$ $-18.8, p=0.00$ ] correspondingly.

\section{Discussion}

Astudy [16] pursued lung function in 75 Amales and females with a mean age of 18.5 years throughout yoga breath-control exercises. Following six weeks of practice, they announced a significant increase in forced vital capacity. Another study [17] was done in individuals who practiced Bhramari Pranayama and adjudged that mean MPD increased for all vowels after practicing Bhramari pranayama. A study [18] on the result of aerobic training and hatha yoga on vital capacity, found out that Aerobic training, hatha yoga, and blend of aerobic and hatha yoga training added significant outcome on the vital capacity of the experimental group. A study on the effect of yoga on vital capacity concluded that there was a significant increase in vital capacity of individuals who practiced yoga [2]. An experiment was conducted [3] where 50 individuals were trained for nine weeks in yoga. The participants were trained for 45 minutes daily, twice a day, and this was done for six days per week. The results showed that when compared to the control group, the vital capacity of the experimental group significantly increased after the completion of the training period. A similar experiment was done [13], and they too found an increase in vital capacity after a period of training. A different study [19] concluded that there was a significant difference in vital capacity before and after yoga training. A positive result of modified yoga technique practice in addition to voice therapy on patients with muscle tension dysphonia, was found [20].

\section{Conclusion}

The prevailing study establishes a positive 1 correlation between practicing yoga and betterment in aerodynamic capacities. The results declare that there was a significant escalation in vital capacity, maximum phonation duration, phonation quotient, and mean airflow rate for individuals who practice regular yoga when compared to people who don't. The outcome of the present study is a preliminary step towards creating an evidence base for the practice of yoga towards overall aerodynamic improvement in healthy adults. Nevertheless, the same needs 
to be researched in the disordered community. Further studies should address this issue in individuals having breathing difficulties such as Asthma, Bronchitis, etc. Additional studies must be carried out on comparing aerodynamic parameters in individuals with varied expertise and period of yoga practice.

\section{References}

1. Barnes PM, Branes PM, Powell Griner E, Mc Fann K, Nihin RL (2004) Complementary and Alternative Medicine use adults. United States Adv data; 27:343: 119.

2. Dr Prabakaran, T. (2016). Effect of Yogic practice on vital capacity. International Journal of Multidisciplinary Education and Research, 1, 43-45.

3. Rajeshwar Reddy, L., Puli Sreehari, \& Mohd Inayatulla Khan. (2015). Effect of Yogic Exercises (Pranayama) on Pulmonary Function Tests.

4. Gudmestad J. Anatomy of Yogi Breathing room. Yoga J (2002); (3) 4: 157-59.

5. Telles S, Nagarathna R, Nagendra HR, Desiraju T (1993). Physiological changes in sports teachers following 3 months of training in yoga. Indian J MedSci. 1993;47(10):235-8. Epub1993/10/01.PMID:8112782.

6. Hutton, Rogers, \& Doan.(2014). Benefits of Yoga Pranayama, Asana, and Meditation Techniques for Classically Trained Singers and Voice Educators. Dissertation, 78.

7. Singh, A. Wisniewski, J. Britton, and A. Tattersfield.(1990) "Effect of yoga breathing exercises (pranayama) on airway reactivity in subjects with asthma," The Lancet, vol. 335, no. 8702, pp. 1381-1383.

8. A. Mooventhan and V. Khode.(2014). "Effect of Bhramari pranayama and OM chanting on pulmonary function in healthy individuals: a prospective randomized control trial," International Journal of Yoga, vol. 7, no. 2, p. 104.

9. L. Nivethitha, N. Manjunath, and A. Mooventhan.( 2017). "Heart rate variability changes during and after the practice of Bhramari pranayama," International Journal of Yoga, vol. 10, no. 2, p. 99.
10. Holger J, Schunemann, Joan Dorn, Brydon JB, Grant, Warren Winkelstein, Jr., Maurizio Trevisan. (2000). Pulmonary Function is a Long-term Predictor of Mortality in the General Population, 29-Year Followup of the Buffalo Health Study. CHEST; 118(3): 656664.

11. Hendreicks, G. (1995). Conscious Breathing, New York, Bantum Books.

12. Frahi, (1996) The Breathing Book, Henry Holt and Co., Inc., New York

13. Dee Ann Birkel (MA), \& Lee Edgren (MS). (2000). Hatha Yoga:- Improved vital capacity of college students. Alternative Therapies, 6.

14. Maslan J, Leng X, Rees C et al (2011) Maximum phonation time in healthy older adults. J Voice 25:709-713

15. M. Kuppusamy, D. Kamaldeen, R. Pitani, J. Amaldas, and P.Shanmugam. (2018). "Effects of Bhramari Pranayama on health-a systematic review," Journal of Traditional and Complementary Medicine, vol. 8, no. 1, pp. 11-16.

16. Joshi LN, Joshi VD, Gokele LV. (1992). Effect of short-term pranayama practice on breathing rate and ventilatory function of lung. Indian J Physiol Pharmacol; 415-427.

17. Usha Manjunatha, Jayashree Bhat, Kumar Radish, Gagan Bajaj, Poovitha Shruthi, Priyanka Nayak, \& Saniya Mariam. (2018). Effect of Bhramari Pranayama on the Acoustic and Aerodynamic Parameters of Voice in Normophonic Females. EvidenceBased Complementary and Alternative Medicine, 2018, 7.

18. Anjumanara Khatun, \& Dr Nita Bandhapadhya. (2016). 1. Effect of aerobic training and hatha yoga on vital capacity of college female students. The International Journal of Academic Research and Development, 1, 44-47.

19. Dr. Baljit Singh Sekhon, \& Dr. P. V. Shelvam. (2016). Effect of selected Yogic practices on vital capacity among university men students. International Journal of Science and Research, 5(5).

20. D. Clement and N. Clement. (2007). Teaching Hatha Yoga, Gabriola Island, British, Columbia, Canada. 